\title{
Wählen Sie Ihr liebstes Titelbild 2015
}

Kinder in der Kunst finden Sie auf jeder Titelseite der pädiatrie hautnah. Mögen Sie es dabei eher klassisch oder doch modern? Helfen Sie uns mit Ihrer Stimme, in Zukunft eine noch bessere Auswahl zu treffen.
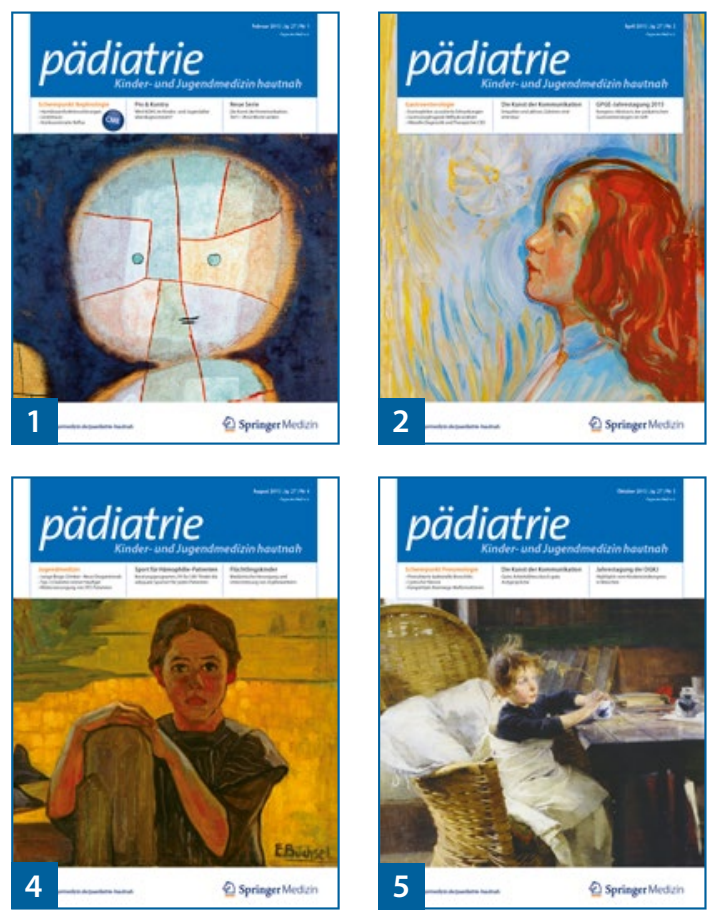

Teilnahme per Fax oder online

Teilnahme-Coupon bitte ausfüllen und bis zum 31. März 2016 an die Redaktion faxen. Alternativ können Sie auch online unter www.springermedizin.de/gewinnspielpaediatrie-hautnah teilnehmen.
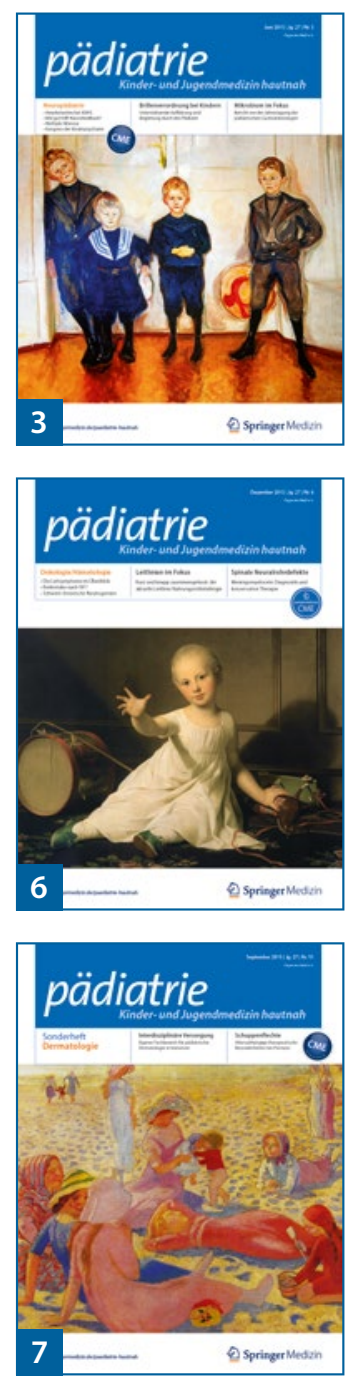

\section{Das können Sie gewinnen}

Unter allen Teilnehmern verlosen wir folgenden Preis:

\section{Preis:}

\author{
200-Euro-Gutschein \\ für ein Fachbuch von
}

\section{Springer Medizin}

\section{Spende für jeden Teilnehmer}

Für jeden, der bei dem Gewinnspiel mitmacht, spendet Springer Medizin

$$
2 \text { Euro an die Refudocs, }
$$

Verein zur medizinischen Versorgung von Flüchtlingen, Asylsuchenden und deren Kindern e.V. Die Refudocs versorgen Flüchtlinge in der Erstaufnahmeeinrichtung der ehemaligen Bayernkaserne in München.

Über ihre Arbeit berichteten wir in der letzten Ausgabe der pädiatrie hautnah.

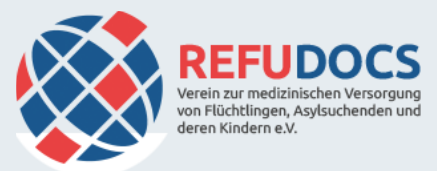

Welches der Titelbilder gefällt Ihnen am besten?
Nr.

Vorname

\begin{tabular}{l} 
Name \\
\hline Straße \\
\hline Postleitzahl Ort \\
FAX: (089) 203043-31405 \\
Eine Barauszahlung der Preise ist nicht möglich. Der Rechtsweg ist ausgeschlossen. Mitarbeiter des Verlags dürfen nicht teilnehmen.
\end{tabular}

